\title{
REVALORIZAÇÃO DO FATO NO AMBIENTE PROCESSUAL CIVIL BRASILEIRO: COMO A HERMENÊUTICA FILOSÓFICA E O PROCESSO CIVIL SE RELACIONAM MESMO NA SOCIEDADE INFORMACIONAL (SOCIEDADE EM REDE)
}

\author{
REVALUATION OF FACT IN BRAZILIAN CIVIL PROCEDURE \\ ENVIRONMENT: HOW THE PHILOSOPHICAL AND CIVIL PROCEDURE \\ HERMENEUTICS RELATE TO THE SAME COMPANY INFORMATIONAL
} (SOCIETY NETWORKING)

FELIPE STRIBE DA SILVA Graduado em Direito pelo Centro Universitário Franciscano, Pós-Graduando em Temas Emergentes em Direito e Novas Tecnologias da Informação e da Comunicação pelo Centro Universitário Franciscano e em Ciências Penais pela Universidade Anhaguera-UNIDERP, pesquisador com ênfase em temas jurídicos e tecnológicos.

\section{RESUMO}

O Processo Civil de viés eminentemente liberalracionalista como se apresenta atualmente no Brasil desvaloriza $o$ fato hipostasiando o direito e desconsiderando a realidade de que este é uma circunstância do fato, não tem condições de dar respostas adequadas a uma Constituição Democrática como é a CF de 1988, pois ainda resta preso ao paradigma fase a fase do procedimento ordinário. A "hermenêutica filosófica" visa solucionar essa defasagem a partir de alterações neste procedimento, que na realidade reflete um apego constitucionalmente inadequado aos paradigmas da cognição exauriente e da noção de processo como busca da verdade, algo que filosoficamente não se sustenta desde o século XX

Palavras-chave: Processo Civil - Constitucionalismo Ordinariedade - Hermenêutica - Revalorização - Fato.

\begin{abstract}
The Civil Procedure bias predominantly liberalrationalist as it stands today in Brazil devalues the fact hipostasiando law and ignoring the reality that this is a condition of fact, not able to give adequate responses to a Democratic Constitution as is the CF 1988, it remains stuck to the paradigm phase to phase of the ordinary procedure. The "philosophical hermeneutics" seeks to address this gap changes from this procedure, which actually reflects a commitment to constitutionally inadequate exauriente paradigms of cognition and the notion of process as the search for truth, something that philosophically does not hold since the twentieth century
\end{abstract}

Keywords: Civil Procedure - Constitutionalism ordinariness - Hermeneutics - Revaluation - Fact;

\begin{abstract}
SUMÁRIO
INTRODUÇÃO; I - ESTADO LIBERAL E PROCESSO CIVIL, COMO FALAR EM EVOLUÇÃO DO CONSTITUCIONALISMO SEM UMA EVOLUÇÃO DO PROCESSO QUE O EFETIVA: DO ABANDONO DO FATO CONCRETO NO ATUAL PROCESSO CIVIL BRASILEIRO; II - "HERMENÊUTICA FILOSÓFICA" DA NECESSÁRIA REVALORIZAÇÃO DO FATO CONCRETO EM UM PROCESSO CIVIL QUE SE DIGA DEMOCRÁTICO, E DE COMO ISSO É PRESSUPOSTO MESMO EM UMA SOCIEDADE EM REDE; CONCLUSÃO; REFERÊNCIAS.
\end{abstract}

REDESG / Revista Direitos Emergentes na Sociedade Global - www.ufsm.br/redesg v. 1, n. 2, jul.dez/2012

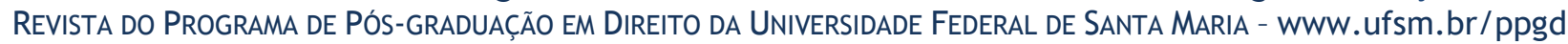




\section{INTRODUÇÃO}

O processo civil brasileiro traz consigo diversas marcas de uma forma de Estado já superada na evolução do constitucionalismo, o Estado Liberal, por isso, ele se mantém alheio a qualquer evolução do campo do direito material, em especial no campo do constitucionalismo.

Uma marca desse apego ao modelo estatal do liberalismo é a eterna (e metafísica, é bom que se diga) busca pela "verdade", e o consequente apego ao vetusto procedimento ordinárioplenário-declaratório, como se o direito processual se bastasse por si mesmo, sendo um instrumento (corrente instrumentalista) a serviço do direito material, mas que não precisa respeitar ou considerar as evoluções que este (próprio direito material) sofreu nas últimas décadas, mormente no seu procedimento.

Mas o mais incrivel é a perda da função essencial (ou substancial) do processo, isto é, a sua função investigativa, com uma cisão (que também é metafísica) entre "matérias de fato" e "matérias de direito", como se o direito não fosse uma circunstância do fato, e além dessa cisão, o que demonstra claramente a perda da função processual investigativa (pois aquela é condição de possibilidade para esta) é a desvalorização da matéria fática no ambiente processual civil brasileiro.

Claramente constata-se que uma das razões, e por que não dizer a principal razão desta “desatualização constitucional” que o processo civil brasileiro sofre atualmente, é a falta de importância do fato, pois este é que irá permitir que as transformações ocorridas no campo do direito material (que é uma circunstância fática) surtem efeitos no processo respectivo, por exemplo, com a afirmação da "questão social" e o consequente surgimento dos direitos econômicos, sociais e culturais, que necessariamente devem invadir o ambiente do procedimento, e que devem fazer com que surjam formas de garantir estes direito, dentro do campo processual.

Entretanto atualmente as discussões acadêmicas quando ao processo ficam, em sua grande maioria, adstritas ao "processo/procedimento (dito) eletrônico", como se o processo pudesse ser alterado apenas e tão somente pelo meio onde ele ocorre, entretanto os grandes pensadores da atual sociedade informacional ou "sociedade em rede" (Manuel Castells) reconhecem que não é a utilização de determinada tecnologia, por si só, que torna determinado instituto adequado à sociedade informacional (entenda-se como sociedade pós-industrial atual). 
Para realmente tornar o processo algo adequado a nossa sociedade (entendendo-se que em um estado constitucionalizado, adequado à constituição, que é social) é necessário um repensar quanto ao procedimento em si ainda apegado ao dogma da ordinarização, como se esta fosse um caminho para a busca da "verdade" (conceito da modernidade), e talvez assim, possamos "atualizar" (que no presente texto não pode ser cindido de "constitucionalizar") o processo civil brasileiro, o que certamente ocorrerá com uma revalorização do fato do ambiente processual, mesmo na era informacional.

\section{I - ESTADO LIBERAL E PROCESSO CIVIL, COMO FALAR EM EVOLUÇÃO DO CONSTITUCIONALISMO SEM UMA EVOLUÇÃO DO PROCESSO QUE $O$ EFETIVA: DO ABANDONO DO FATO CONCRETO NO ATUAL PROCESSO CIVIL BRASILEIRO.}

O ambiente processual civil brasileiro ainda preso a um paradigma de uma filosofia da consciência, que com fundamento no esquema sujeito-objeto acredita na noção iluminista e liberal de que se podem submeter os objetos aos sujeitos, e que a linguagem, por sua vez seria um mero instrumento nesse processo.

O Estado liberal, também chamado Estado Moderno tem por base o liberalismo, este por sua vez teve dois "elementos originários", um primeiro foi o pensamento filosófico do séc. XVII e XVIII, representado por Jonh Locke, Jean Jacques Rousseau, Adam Smith, Thomas Paine, Von Humboldt, Tocqueville, Stuart Mill, dentre outros, e um segundo foram os movimentos políticos, econômicos e sociais, como por exemplo, a Revolução Francesa, a Revolução Industrial, a Revolução Americana.

O termo liberalismo dá margem a diferentes conotações/sentidos, por exemplo, nos Estados Unidos, o termo liberal remete a um posicionamento político de direita, defensor radical de velhas e novas liberdades civis, já na Itália, o termo liberal remete àqueles que procuram manter a livre iniciativa econômica e a propriedade particular. 0 uso do termo no Brasil aproxima-se desse sentido.

No plano das ideias, também há discrepância no uso do termo. Há o liberalismo jurídico (é exatamente a ideia de Estado de Direito, ou seja, preocupação em garantirem-se os direitos fundamentais, por meio do Direito, contra o arbítrio estatal), o liberalismo econômico (é a ideia REDESG / Revista Direitos Emergentes na Sociedade Global - www.ufsm.br/redesg v. 1, n. 2, jul.dez/2012 REVISTA Do PROGRAMA de Pós-GRAdUAÇão EM DIREITO dA UNIVERSIDADE FEDERAL DE SANTA MARIA - www.ufsm.br/ppgd 
de que a economia deve ser deixada a cargo do mercado, ou seja, o mercado regula a si próprio, a mão invisível) e o liberalismo político (é o meio-termo entre revolução e conservadorismo, assim surgem idéias de reforma política, de mobilidade).

Benjamin Constant desenvolveu a antítese entre liberdades positivas e liberdades negativas. Segundo ele, liberdade positiva é a liberdade dos antigos, enquanto liberdade negativa é a liberdade moderna, inventada pelos liberais. A liberdade positiva seria a liberdade que se manifesta politicamente, a liberdade de dar a si mesmo a própria lei (como ocorria em Atenas e em Roma); já o termo negativo traz a ideia de abstenção, de não-intervenção.

O Estado liberal é aquele Estado fundado na idéia de liberdade, e em nome dela esse estado procura limitar o poder político. Nessa definição sintética, um ponto que precisa ser chamado atenção, e que esse estado se desenvolve a partir de uma preocupação estatal, de colocar uma limitação ao exercício do poder, para a defesa.

E, caracterizando essa forma de Estado afirma-se que:

$\mathrm{Na}$ virada do século XVIII, entretanto, essa mesma classe (a classe burguesa) não mais se contentava em ter o poder econômico, queria, sim, agora, tomar para si o poder político até então privilégio da aristocracia, legitimando-a com um poder legal-racional, sustentado em uma estrutura normativa a partir de uma "Constituição" - no sentido moderno do termo - como expressão fundamente do modelo político fundante do Estado ${ }^{1}$.

Antes havia um estado absolutista em que o poder era concentrado todo nas mãos do rei, e com isso tínhamos uma situação em que os sujeitos ficavam submetidos ao arbítrio estatal. 0 Estado Liberal surge com essa preocupação de proteger a liberdade dos indivíduos em face do poder do Estado.

Conforme Paulo Bonavides "Com efeito, observava-se em quase toda a Europa continental, sobretudo em França, a fadiga resultante do poder político excessivo da monarquia absoluta, que pesava sobre todas as camadas sociais interpostas entre o monarca e a massa de súditos ${ }^{2}$.

Ele é um estado que defende uma concepção de estado mínimo que é oposto a um estado máximo que concentra o poder e tenta tratar de todos os assuntos.

Cabe ao Estado à preocupação apenas com a manutenção da ordem seja interna, seja em

\footnotetext{
${ }^{1}$ STRECK, Lenio Luiz; MORAES, José Luiz Bolzan. Ciência Política e Teoria Geral do Estado, $5^{a}$ Edição, Ed. Livraria do Advogado, 2009, p. 39.

${ }^{2}$ BONAVIDES, Paulo. Ciência Política, 10 ed. Malheiros, São Paulo, 1999, p. 166.

REDESG / Revista Direitos Emergentes na Sociedade Global - www.ufsm.br/redesg v. 1, n. 2, jul.dez/2012 Revista do Programa de Pós-graduaçÃo em DIREITO dA Universidade FEderal de SANTA MARIA - www.ufsm.br/ppgd
} 
relação aos Estados estrangeiros, é pela manutenção dessa ordem, pela defesa do direito, pela observância das normas jurídicas que se defende a liberdade das pessoas.

O Estado liberal, em comparação com o Estado absolutista que veio antes dele, traz diversas idéias novas: Ao invés da tradição o Estado Liberal introduz a idéia de contrato social, como fundamento, a soberania nacional é fundada na vontade geral do povo, ao invés da figura do Rei, no Estado Liberal passa a haver o exercício do poder pelos representantes eleitos do povo. O Estado absolutista se baseia na ideia de "razão do estado", já o Estado liberal age como aquele que tem a função de executar e de proteger as normas jurídicas.

Surgem, no Estado Liberal, diversos instrumentos técnico-jurídicos para a proteção dos indivíduos: a Constituição, o Princípio da Legalidade, a Declarações de Direitos Fundamentais, o Princípio da separação dos poderes a Representação Política (a lei só é valida se criada por representantes do povo).

Conforme se afirma, quando a separação de poderes no Estado Liberal, pois

Ao resguardar os direitos de liberdade, o modelo liberal principalmente na França encontrou na teoria da separação dos poderes a matriz de sua constituição, estruturando a salvaguarda das liberdades na decomposição da soberania numa pluralidade de poderes ${ }^{3}$.

Como um direito com origem em uma revolução motivada pela classe burguesa, esse direito no Estado Liberal, através de um constitucionalismo liberal, se preocupou apenas em tão somente com os direitos que importavam a essa classe, isto é, os direitos civis (em especial a liberdade, pois permitia o livre exercício do comércio, principal preocupação burguesa) e os direitos políticos (pois permitiam a manutenção do poder).

Ao judiciário nesse estado liberal foi relegada uma função de simples "declaração" das vontades expressadas pelo legislador, principalmente pelo motivo, histórico, de que muitos dos membros da aristocracia permaneceram no poder em cargos da judicatura, e precisavam ter a sua interpretação limitada.

Aqui se encontra a origem do chamado "positivismo exegético/sintático", que com influência de Augusto Comte, passou a defender que a ciência do direito deveria se confundir

\footnotetext{
${ }^{3}$ ISAIA, Cristiano Becker. Processo civil, atuação judicial e hermenêutica filosófica. $2^{\text {a }}$ edição. Curitiba: Ed. Juruá, 2011, p. 32.

REDESG / Revista Direitos Emergentes na Sociedade Global - www.ufsm.br/redesg v. 1, n. 2, jul.dez/2012 ReVISTA do Programa de Pós-graduação em DiReito da Universidade Federal de SANTA MARIA - www.ufsm.br/ppgd
} 
com as regras jurídicas previstas, pois o papel do jurista seria tão somente ter a capacidade de procurar na ordem jurídica posta à norma que melhor se enquadre naquele caso concreto.

Entretanto essa visão de direito, acabou por provar-se insuficiente para a efetivação da autonomia da ciência do direito, surgindo assim uma nova forma de positivismo, que, por sua vez, teve como corifeu Hans Kelsen (a partir da sua obra “Teoria Pura do Direito”), defendeu que o direito deveria ter como seu objeto de estudo a norma jurídica, e que esta teria o seu fundamento de validade em uma norma superior (surgindo a idéia escalonada ou piramidal da ordem jurídica).

E para esse "positivismo normativista/semântico", ao contrário do exegético quando o juiz não encontrasse no sistema a referida norma jurídica para aquele caso, ele deveria "dentro dos contornos que esse próprio sistema dava" tomar uma decisão que poderia advir de sua consciência. Nasce aqui o que François Ost chamou de "Modelo Júpiter de Juiz", que sem se importar com o fato apenas busca a norma jurídica adequada para aquele caso concreto, e quando não a encontra recorre a sua "intima convicção".

O processo civil assim foi pensado para a proteção destes direitos (civis e políticos), surgindo assim um germe do moderno "processo/procedimento ordinário", que poderia estender-se no tempo indefinidamente, pois não se desejava que o juiz ao final alterasse qualquer realidade apenas declara-se que aquele determinado indivíduo (burguês) era livre para negociar ou tinha direito de participar do processo político.

O Estado liberal surge no século XVIII na Europa e depois na América, e após o século XIX ele se espalha pelo mundo, e na segunda metade do Século XIX esse estado começa a entrar em crise, e na primeira metade do Século XX, ele efetivamente começa a ser repensado. Entretanto as extremas desigualdades que esta forma de estado (de feição liberal) causou, no final do século XIX e inicio do século XX fizeram com que ele se apercebesse de suas insuficiências para proteger as demandas da sua sociedade que, por ser livre, e politicamente participante exigia.

$E$, de forma também revolucionária, os movimentos grevistas do inicio do século $X X$ provaram que era inviável a manutenção de um Estado extremamente absenteísta, e que isso acabava por se tornar também economicamente inviável.

O Estado Social é aquele Estado que é fruto da chamada "questão social”, e que se constitui com a intenção de se suceder ao Estado Liberal. Essa forma de Estado se constituiu a partir de duas preocupações principais: Um esforço de aprofundamento e de alargamento da liberdade e da igualdade material (democracia de massas). O Estado social é um Estado que se 
preocupa em intervir nas relações econômicas. Pois o instrumento que ele encontra para desenvolver essa igualdade material é através da intervenção na economia, na regulação das relações de trabalho, na integração política de todas as classes sociais.

Observam-se algumas constituições que seguiram essa diretriz: como a Constituição Mexicana de 1917 e Constituição Alemã de Weimar de 1919, e outras que ainda a seguem tais como a Constituição Italiana de 1947, a Constituição Alemã de 1949, a Constituição Portuguesa de 1976, a Constituição Espanhola de 1978 e, por fim a Constituição Brasileira de 1988.

Assim evoluímos de um estado abstenteísta e irresponsável para um estado constitucionalmente interventor e que pretendia mudar o status quo em que estava inserido, surge aqui, no âmbito do direito constitucional, uma nova preocupação para o Estado, a preocupação com os direitos sociais, econômicos e culturais.

Conforme afirma Cristiano Becker Isaia ${ }^{4}$

A partir de tal momento o direito pretende deixar um estado de esclerose funcional (verificável no estado de espectro Liberal) para se tornar ator ativista, o que leva á aproximação do Estado para com a sociedade, dada mesmo a função promocional de sua nova roupagem.

Estes direitos, com um objetivo transformador, pretendiam que a sociedade, do início do séc. $X X$ se tornasse menos desigual, e que de alguma forma o sistema político pudesse atuar como forma de alterar o sistema jurídico, promovendo uma alteração do sistema econômico. $E$ para superar de vez com o positivismo, que é uma herança liberal-burguesa que Estado moderno, nessa sua segunda feição, aproximando-se da sociedade, assume contornos mais atuantes, e, em especial a atuação do judiciário, torna-se mais “discricionário para atender a aplicação de um direito que se torna mais principiológico e mais aberto exigindo por consequência uma atuação mais presente do magistrado ${ }^{5}$ ".

Assim, é que o papel do judiciário se altera, ele deixa de ter uma função estática e assume um papel modificador da realidade, assim o juiz passa a buscar alterar a sua realidade, afastando-se da idéia clássica de norma jurídica para adotar uma posta que se auto-intitula “pós-positivista”. Surge aqui, para François Ost a figura do “Modelo de Juiz Hércules”, capaz de

\footnotetext{
${ }^{4}$ ISAIA, Cristiano Becker. Processo civil, atuação judicial e hermenêutica filosófica. $2^{\mathrm{a}}$ edição. Curitiba: Ed. Juruá, 2011, p. 39.

${ }^{5}$ LUCAS, Doglas Cesar. A crise funcional do Estado e o cenário da Jurisdição desafiada. In: MORAIS, José Luís Bolzan de. O Estado e suas crises. Porto Alegre: Livraria do advogado, 2005, p. 183.

REDESG / Revista Direitos Emergentes na Sociedade Global - www.ufsm.br/redesg v. 1, n. 2, jul.dez/2012 Revista do Programa de Pós-graduaçÃo em DIREITO dA Universidade Federal de SANTA MARIA - www.ufsm.br/ppgd
} 
REVALORIZAÇÃO DO FATO NO AMBIENTE PROCESSUAL CIVIL BRASILEIRO: COMO A HERMENÊUTICA FILOSÓFICA E O PROCESSO CIVIL SE RELACIONAM MESMO NA SOCIEDADE INFORMACIONAL (SOCIEDADE EM REDE)

FELIPE STRIBE DA SILVA

com suas ações alterar o status quo existente, mas isso não através de um positivismo exegético, mas sim através da busca por valores que podem ser extraídos de um texto constitucional dirigente.

Entretanto essa transformação de papéis da magistratura não ocorreu de uma forma constitucionalmente adequada, mas sim dentro de um paradigma da consciência dos magistrados, como se eles através de sua experiência dita "superior" pudessem concretizar a realidade do estado constitucional social, e isso dentro de um procedimento ordinário-plenáriodeclaratório, que com uma função meramente instrumental não influísse na resposta dada por esse magistrado, quando e como lhes conviesse, e ao fazer isso não ser positivista, lembrando que o positivismo também pode ser semântico/normativista, e não tão somente exegético/sintático.

Mas afinal qual será o pior, nesse século inseguro (Sec. XXI) um juiz Júpiter (positivista exegético, que apenas e tão somente declara a previsão da lei) ou um juiz Hércules (positivista normativo, preso a perspectiva da sua própria consciência, que extraí sentidos do texto)? Essa é uma pergunta que pode ser respondida como afirma Cristiano Becker Isaia ${ }^{6}$ no momento em que

Se supere a figura do juiz solipsista, o qual decide de acordo com sua 'vontade', 'experiência', etc... interpretando, quando pouco (somente nos casos difíceis pelo método do sopesamento), para descobrir o conteúdo da norma, extraindo o 'significado ideal' do texto... em seu lugar impõe a atuação de um juiz que tenha ciência da responsabilidade social e política de suas decisões, buscando dar coerência e integridade ao direito, ciente de sua responsabilidade ante uma Constituição diretiva fundamental.

Mas aparentemente não é o que o nosso sistema pretende, basta uma analise de alguns dispositivos do nosso atual Código de Processo Civil (melhor denominado código de procedimento), para que se perceba como o fato concreto cada vez mais perde espaço, em um rito ordinário, apegado a filosofia da consciência e a ordinariedade.

Inicialmente temos a previsão do art. 285-A do Código de Processo Civil, denominada “Improcedência prima facie" que prevê: Quando a matéria controvertida for unicamente de direito e no juízo já houver sido proferida sentença de total improcedência em outros casos idênticos, poderá ser dispensada a citação e proferida sentença, reproduzindo-se o teor da anteriormente prolatada.

\footnotetext{
${ }^{6}$ ISAIA, Cristiano Becker. Processo civil, atuação judicial e hermenêutica filosófica. $2^{\text {a }}$ edição. Curitiba: Ed. Juruá, 2011, p. 107.

REDESG / Revista Direitos Emergentes na Sociedade Global - www.ufsm.br/redesg v. 1, n. 2, jul.dez/2012

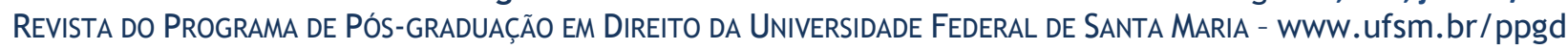


Em primeiro lugar será que existe matéria “unicamente de direito”? Obviamente que não, o direito é um elemento circunstancial do próprio fato, e, portanto sempre pressupõe este fato. Em segundo lugar será que existem casos idênticos? Obviamente que não, todo o caso por mais semelhante que seja a outros, guarda as suas peculiaridades que devem ser analisadas. Por fim, em terceiro lugar, o juiz pode simplesmente reproduzir o teor de uma sentença anteriormente prolatada? Ou será que isso fere algum princípio? É claro que fere o princípio do acesso a justiça, ou da inafastabilidade da jurisdição, esse sim um princípio decorrente de uma regra esculpida no texto constitucional no art. $5^{\circ}$ inciso XXXV.

Após temos a previsão do art. $518 \$ 1^{\circ}$ do Código de Processo Civil, denominada "sumula impeditiva de recursos" ex vi légis: 0 juiz não receberá o recurso de apelação quando a sentença estiver em conformidade com súmula do Superior Tribunal de Justiça ou do Supremo Tribunal Federal. Será que a previsão de uma sumula pode ser simplesmente reproduzida em outros casos? Para melhor responder a essa pergunta, nada melhor que o excelentíssimo magistério do professor Ovídio Batista ${ }^{7}$ que afirmou:

A linguagem expressa na sentença terá - hoje - uma compreensão cujo sentido não será adequado para o intérprete que houver de lidar com um texto passado algum tempo...Daí o conflito, por exemplo, entre a nossa realidade cultural e a aspiração das sumulas vinculantes, que aprisionam o direito ao passado, tornando o "certo" indefinidamente certo.

E por fim, temos a previsão do art. 543-C do Código de Processo Civil, e os denominados (erroneamente, é bom que se diga) “recursos repetitivos" que prevê: Quando houver multiplicidade de recursos com fundamento em idêntica questão de direito, o recurso especial será processado nos termos deste artigo.

Este dispositivo se não é o mais paradigmáticos dos até aqui citados, e o mais assustador é a sua reprodução no Anteprojeto de Código de Processo Civil, com o chamado "incidente de resolução de demandas repetitivas" previsto no artigo 895 que prevê: “É admissível o incidente de demandas repetitivas sempre que identificada controvérsia com potencial de gerar relevante multiplicação de processos fundados em idêntica questão de direito e de causar grave insegurança jurídica, decorrente do risco de coexistência de decisões conflitantes”. Ainda, com

\footnotetext{
${ }^{7}$ SILVA, Ovídio A. Baptista da. Epistemologia das ciências culturais. Porto Alegre: Ed. Verbo Jurídico, 2009 , p. 40.

REDESG / Revista Direitos Emergentes na Sociedade Global - www.ufsm.br/redesg v. 1, n. 2, jul.dez/2012 Revista do Programa de Pós-graduaçÃo em DIREITO dA Universidade Federal de SANTA MARIA - www.ufsm.br/ppgd
} 
a previsão do art. 903: Julgado o incidente, a tese jurídica será aplicada a todos os processos que versem idêntica questão de direito.

Como afirma a melhor doutrina:

É nesse tipo (liberal racionalista) de ambiente processual que se rotulam as lides, ignorando-se sua singularidade, acondicionando-as numa espécie de pacto de 'casos' (cases package), a cada qual se atribuirá uma única decisão solucionadora, o que até vem expresso no artigo 903 do Anteprojeto! É assim que o caso concreto, pouco a pouco, continua perdendo lugar no espaço processual ${ }^{8}$

E a desvalorização do fato traz consigo a desvalorização da "obrigação de motivar" como afirma o professor Lenio Streck?

Vivenciamos uma forte tendência reformista no sentido de sacrificar o aspecto qualitativo da prestação jurisdicional, em favor de uma espécie de aceitação da prestação institucional de 'flexibilização do dever fundamental de fundamentar' por motivos pramaticistas - morosidade da justiça, excesso de demandas, falta de serventuários, etc.-criam-se mecanismos de reprodução por atacado das decisões.

Dessa forma se passa a ter uma completa desvalorização do fato, e começa a produção dos chamados cases package, submetendo o fato concreto à pré-compreenções que nada tem a ver com ele, o que desestrutura a função do processo judicial e consequentemente da própria democracia, que tem ele como um dos seus principais instrumentos.

\section{II - “HERMENÊUTICA FILOSÓFICA” DA NECESSÁRIA REVALORIZAÇÃO DO FATO CONCRETO EM UM PROCESSO CIVIL QUE SE DIGA DEMOCRÁTICO, E DE COMO ISSO É PRESSUPOSTO MESMO EM UMA SOCIEDADE EM REDE.}

Há alguns anos ocorreu na filosofia em geral o que muitos autores caracterizam com um verdadeiro "giro hermenêutico-ontológico", uma "revolução copernicana”, como afirma o

\footnotetext{
${ }^{8}$ ISAIA, Cristiano Becker. Processo civil, atuação judicial e hermenêutica filosófica. $2^{\mathrm{a}}$ edição. Curitiba: Ed. Juruá, 2011, p. 60.

${ }^{9}$ STRECK, Lenio Luiz. OLIVEIRA, Rafael Tomaz de. 0 que é Isto vol. 02 - Garantias Processuais Penais. Porto Alegre: Livraria do Advogado, 2012, p. 97.

REDESG / Revista Direitos Emergentes na Sociedade Global - www.ufsm.br/redesg v. 1, n. 2, jul.dez/2012 Revista do Programa de Pós-graduaçÃo em DiREITO dA Universidade FEderal de SANTA MARIA - www.ufsm.br/ppgd
} 
REVALORIZAÇÃO DO FATO NO AMBIENTE PROCESSUAL CIVIL BRASILEIRO: COMO A HERMENÊUTICA FILOSÓFICA E O PROCESSO CIVIL SE RELACIONAM MESMO NA SOCIEDADE INFORMACIONAL (SOCIEDADE EM REDE)

professo Lenio Streck, que possibilitou que a filosofia adentrasse no mundo prático através da linguagem.

A hermenêutica filosófica é uma construção teórica que vai tentar superar a metodologia tradicional do Direito. Fazendo uma análise etimológica do termo "hermenêutica" vem do substantivo grego "hermeneia" que tem a ver com o estudo da interpretação, ela investiga como se dá a interpretação, ela investiga as condições da interpretação. Trata-se de uma ciência que lida com o "problema da interpretação" e,segundo alguns, a origem dessa doutrina vem do deus "Hermes" que era o mensageiro dos deuses que trazia a mensagem dos seres superiores para os humanos.

Através de um desenvolvimento histórico da "hermenêutica enquanto filosofia" (que não se confundo com método de interpretação) deve-se estudar inicialmente Friedrich Schleiermacher $(21 / 11 / 1768$ - 12/02/1834), este autor é considerado o pai da "hermenêutica moderna", trata-se de uma figura que tem importância no seu desenvolvimento, entretanto deve-se referir que ele realiza as suas considerações voltando-se para o campo da religião, uma vez que foi um teólogo.

Schleiermacher observou que a interpretação é algo que vai além daquilo que tem a ver com a percepção da estrutura gramatical do texto. Entretanto ele aponta uma preocupação que se deve ter no ato de se interpretar, que é o sentido real do texto, há intenções, há uma psicologia atrás do texto, que devemos buscar compreender aquilo que se encontra no fundo daquele texto.

O autor trabalhava com duas dimensões: A denominada "pré-compreenção", que consiste no ato de interpretar, e envolve a percepção de que o ato de interpretar não parte do nada. Sempre que se interpreta leva-se algo em consideração uma série de percepções do passado, o ato de interpretar envolve pré-conceitos, pré-julgamentos que já estão enraizados no ser, e isso tudo interfere no ato de interpretar.

Aqui ele trabalha com algo que se costuma chamar de "circulo hermenêutico" se toda a interpretação exige pré-conhecimento, e por isso toda a interpretação é "interpretação de interpretação", por tanto a interpretação é um circulo, ela sempre remete a outra interpretação anterior de mundo que já se tinha, pois cada um traz consigo determinada bagagem que pode ser diferente. 
E a denominada “compreensão", nesse ponto é preciso ao interprete adentrar no contexto da obra, ele deve buscar tentar entrar no contexto que levou a produção da obra, devemos entrar na dimensão do autor da obra. Conforme Cristiano Becker Isaia ${ }^{10}$

É flagrante no pensamento de Schleiermacher, o abandono do objeto da hermenêutica antiga, isso porque ao invés de mediar um sentido, uma verdade, interessava a ele um ato de criação do autor, considerando os textos como fenômenos de expressão (...) o pensamento Schleimacher é fundamental para que seja possível entender o processo compreensivo hermenêutico a partir da posição ocupada pelo interprete, não apenas voltado unicamente para a verdade em causa.

Outro importante autor para a hermenêutica filosófica (que como já dito é filosofia e não método de interpretação) é o psicalista Wilhelm Dilthey (19/11/1833 - 01/10/1911), que foi o autor que pela primeira vez pensou em estabelecer a hermenêutica como a metodologia própria das "ciências humanas",

Dilthey traça diferenças entre as ciências naturais e as ciências humanas, pois enquanto aquelas têm a ver com descrever, explicar os fenômenos, estas envolvem compreender os fenômenos. Como as ciências humanas tem uma característica diferente, pois elas lidam com a compreensão de realidades socioculturais, o método seria o método hermenêutico.

Para ele é fundamental compreender que o fato humano é um fato histórico, a cultura e o homem são produtos da história (extremamente historicista), devemos compreender que o nosso mundo é um mundo dotado de historicidade que se altera de acordo com as mudanças históricas.

Conforme entende a doutrina em Dilthey ${ }^{11}$ :

A interpretação de um texto se desvelaria desde sua assumida função como mediador de um nexo histórico mais amplo, completo na perspectiva universal. 0 novo ponto de partida de Dilthey será a filosofia da vida, categoria que expressará a necessidade de outra espécie de ciência, diversa da ciência da natureza (...) as ciências do espírito devem compreender a vida a partir de categorias delas derivadas, razão pela qual o caráter do individuo é uma unidade compreensível em si mesma, manifestando-se através de exteriorizações de sua vida, local onde todas as coisas surgem a partir da consciência sobre o seu condicionamento.

\footnotetext{
${ }^{10}$ ISAIA, Cristiano Becker. Processo civil, atuação judicial e hermenêutica filosófica. $2^{\text {a }}$ edição. Curitiba: Ed. Juruá, 2011, p. 80/81

${ }^{11}$ ISAIA, Cristiano Becker. Processo civil, atuação judicial e hermenêutica filosófica. $2^{a}$ edição. Curitiba: Ed. Juruá, 2011, p. 82/83.

REDESG / Revista Direitos Emergentes na Sociedade Global - www.ufsm.br/redesg v. 1, n. 2, jul.dez/2012

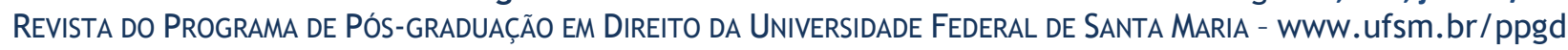


REVALORIZAÇÃO DO FATO NO AMBIENTE PROCESSUAL CIVIL BRASILEIRO: COMO A HERMENÊUTICA FILOSÓFICA E O PROCESSO CIVIL SE RELACIONAM MESMO NA SOCIEDADE INFORMACIONAL (SOCIEDADE EM REDE)

Mas sem dúvida o mais importante autor da "hermenêutica filosófica" foi Martin Heidgger (26/09/1889 - 26/05/1976), ele é um autor muito importante para o desenvolvimento da filosofia do século XX. E a sua filosofia terá um enorme impacto ao longo deste século, surgem diversos filósofos, influenciados por ele, Sartre, Foucalt, Hanna Arendt, Gadamer.

Ele compreende a hermenêutica como um "elemento existencial do homem", é como se para ele a existência do homem fosse uma existência hermenêutica, a existência humana é ontologicamente hermenêutica (o homem é um ser cuja sua essência é a interpretação), e nesse sentido a interpretação é algo existencial. Ele cria uma série de termos próprios, por exemplo:

O homem é o "Ser-aí" (Dasein), nesse sentido o homem é o ente que se propõe a pergunta sobre o sentido do ser, ele é aquele ente, aquele animal cuja pergunta incessante é: “o que é o existente?”. E, segundo Heidegger, esse termo indica o fato de que o homem estará sempre lançado nesta relação, de um modo ativo, no sentido de que ele sempre interpreta o mundo, ele sempre tenta modificar o mundo, que sempre será a sua construção.

Conforme ele afirma: “Esse ente, que nós mesmos já somos sempre e que tem, entre as outras possibilidades de ser, a de buscar, nós o indicamos como o termo Ser-aí (Dasein)". Se, é assim o homem é a essência sobre a possibilidade de vir a ser algo, o homem é o projeto, pois o homem é possibilidade, de modo que ele não existe no mundo de um modo impassível ele altera o mundo, ele constrói o mundo.

Martin Heidegger tem uma preocupação extrema com a linguagem, ele associa a linguagem á explicação de como o homem conhece as coisas, para ele a capacidade que se tem de conhecer as coisas é algo que de certa forma se explica com a linguagem.

Para ele a linguagem é uma das coisas que constitui o homem, a linguagem, ao mesmo tempo, que permite chegar a determinados resultados, ela também estabelece limites intransponível com relação à capacidade de se conhecer. Conforme o filósofo alemão nós não somos capazes de chegar a verdade em relação às coisas, não é possível para os seres humanos chegar a uma verdade que esta escondida em algum lugar, e com algum esforço vamos chegar a ela, a verdade nós não vamos atingir, pois estamos limitados pela linguagem.

O homem constrói conhecimentos através da linguagem, se as coisas são construídas e não descobertas pelo ser, nós não descobrimos a verdade, nós a construímos, e isso quer dizer que as coisas têm um passado, uma história, e isso é extremamente importante para compreender aquilo que precisamos compreender. 
Um quarto e não menos importante marco teórico da hermenêutica filosófica é HansGeorg Gadamer (11/02/1900 - 13/03/2002), discípulo de Heidgger, ele afirma que a hermenêutica se funda na experiência global que o ser adquire ao longo da vida. Quando o agente interpreta essa experiência de algum modo vem à tona, isso é fundamental pra compreender e tentar construir o que deve ser uma interpretação correta uma interpretação adequada.

Como o individuo é marcado pela sua formação, educação, meio social, o seu ato de interpretar sofre influência dessas marcas, assim o essencial para realizar uma interpretação correta é se chegar a um ponto em que se possa evitar esses hábitos mentais inconsciente que o ser tem ao interpretar. Quando ele não consegue isso inconscientemente ele coloca as suas experiências passadas no ato de interpretar.

Assim, para Gadamer, essa interpretação deve partir de um ponto onde se reconheça que o interprete tem um passado, para que ele não seja traído por esse passado, para que ele posse separar as suas vivências pessoais daquilo que está no texto. Isso é um ato incessante, segundo ele o homem nunca para de interpretar, e o pressuposto fundamental é tomar consciência do pré-conceitos do interprete (conceitos formados anteriormente ao ato de interpretar), da sua história, e para isso deve-se conseguir cindir aquilo que esta no texto daquilo que esta no seu inconsciente. Surgem dois questionamentos:

Um primeiro: seguindo a teoria de Gadamer, qual é a condição para se compreender?

Para ele essa condição tem a ver com uma sensibilidade para a alteridade do texto, da seguinte forma, uma vez gerado o texto, ele passa a ter vida própria ele não se prende ao autor que o editou, pois à medida que o tempo vai passando as interpretações também podem se alterar, nesse sentido a interpretação é, portanto também um processo histórico. Pois no ato de interpretar, tanto o interprete quanto o texto, tem a sua própria história.

E consequentemente um segundo: Qual seria a contribuição da Hermenêutica para a interpretação do Direito? A contribuição seria que ela aponta a insuficiência das concepções tradicionais de interpretações, ela mostra que as regras tradicionais de interpretação do Direito, criadas por Rudolf Von Savigni, são insuficientes em face da construção hermenêutica. “ $A$ hermenêutica mostra que a interpretação se funda da práxis da vida, com a vida prática, ou seja, tem a ver com aquilo que a gente experimenta na nossa vida"

Dessa forma a hermética acaba afastando a interpretação daquele cientificismo no sec. XIX, ela acaba mostrando que a interpretação não é científica, e desta forma ela acaba 
contribuindo para o ressurgimento da interpretação objetiva, pois se o texto tem uma história própria à finalidade buscada no texto também deve ser adequada ao momento vivido.

Assim com a hermenêutica filosófica quebra-se a clássica relação “sujeito-objeto", em prol de uma relação que de fato ocorre entre "sujeito-sujeito" e identifica-se que a linguagem não é um terceiro elemento, mas sim uma condição de possibilidade dessa relação, e que não se extraí sentidos dos objetos mais sim se atribui sentido a eles, isso se deve aos trabalhos de pensadores como Martin Heidegger e Hans Hoer Gadamer.

Ainda, como grande contributo de Heidegger, temos a questão de que ele constata que o individuo não interpreta para compreender para após aplicar, mas sim que ele já compreendeinterpreta-aplica desde sempre como “ser-ái” (dasein), como ser no mundo que já está integrado a uma dada realidade.

Assim é importante uma correta compreensão dos princípios (e não da pan-principiologia que impera no ambiente jurídico nacional), pois eles de certa forma irão garantir uma integridade e coesão das interpretações consideradas "autênticas" numa dada realidade constitucional. Sem dúvida um dos primeiros a trabalhar com este tema dos princípios, já em uma visão contemporânea foi o professor Ronald Dworkin na obra “Levando os Direitos a Sério" (1977), onde basicamente, conforme resume a sua primeira fase o professor Adrian Sgarbi ${ }^{12}$ :

Seu ponto forte é compreensão de que o positivismo jurídico se equivoca ao pensar o direito como fatos objetivos, ou seja, como elementos passíveis de identificação por um critério de pedigree. Porque pensar dessa forma é excluir um dos elementos capitais para a compreensão do direito, os princípios... Dada cegueira das teorias antecessoras de não verem os princípios, a eles passa sem ser notado o papel de os princípios oferecerem uma resposta certa aos casos difíceis.

Os princípios são importantes, neste processo, pois eles permitem uma visão ética nessa compreensão e conforme a professora Carla Farali, esta visão faz parte de um dos cinco grandes vetores da filosofia contemporânea nas ultimas décadas, isto é, a "abertura da filosofia do direito para aos valores ético-políticos ${ }^{13}$ ".

\footnotetext{
${ }^{12}$ SGARBI, Adrian. Clássicos da teoria do Direito. Rio de Janeiro: Lúmen Júris, 2006, p. 194.

${ }^{13}$ FARALI, Carla. A filosofia do Direito Contemporâneo. Madrid: Hispania Libros, 2007, p. 17.

REDESG / Revista Direitos Emergentes na Sociedade Global - www.ufsm.br/redesg v. 1, n. 2, jul.dez/2012

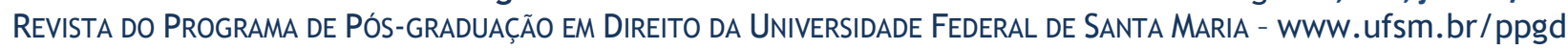


Como sua clareza e coragem costumeiras o processualista Ovídio Batista ${ }^{14}$ demonstrou que enquanto não for quebrado o paradigma da subsunção ainda haverá um positivismo, ele afirmou que:

Com efeito, é a subsunção que permite que nossos magistrados - utilizando a lei como premissa maior do silogismo judicial - abandonem o 'fato' e suas circunstancias (art. 131 do CPC) para, como o que dele resta, identificá-lo com os demais 'fatos' igualmente despidos de suas individualidades, jogando-os na norma, como exemplares de uma seriação de casos, pretensamente idênticos, mesmo que circunstancialmente entre si diversos

E aqui, fazendo uma crítica a Ronald Dworkin haverá discricionariedade mas essa deverá aparecer no caso e não como uma regra, pois a hermenêutica, já provou que o interprete tem um fato histórico nas mãos, seja um documentos, uma prova, e jamais um conjunto análogo de episódios ${ }^{15}$.

Como afirmou Cristiano Becker Isaia ${ }^{16}$

A tarefa de Ovídio Baptista na referida obra, foi a de verificar ou não a existência da discricionariedade judicial, investigando se o sistema jurídico reconheceria a seus magistrados essa parcela de discrição, de escolha entre duas ou mais alternativas legítimas, assim consideradas pelo sistema. E o fez a partir da crítica ao modelo de Dworkin, partindo da premissa de que este se preocupa unicamente com o direito, não com os fatos, compromisso nitidamente racionaliluminista.

Entretanto contrariando o entendimento de Ovídio o jurista gaúcho Lenio Streck ${ }^{17}$ entende que não é possível qualquer discricionariedade, ele afirma que na realidade

Se o método para o paradigma da filosofia da consciência é/foi o supremo momento da subjetividade, decretar a sua superação, como magistralmente fez Gadamer, não quer dizer que a partir de então se posse dizer qualquer coisa sobre qualquer coisa, ou qualquer coisa que a consciência nos impõe, ao contrario: se o método colocava a linguagem em um plano secundários (terceira coisa entre o sujeito e o objeto) manipulável pelo sujeito solipsista, a intersubjetividade que se

\footnotetext{
${ }^{14}$ SILVA, Ovídio A. Baptista da. Epistemologia das ciências culturais. Porto Alegre: Ed. Verbo Jurídico, 2009, p. 30.

${ }^{15}$ Idem, ibidem, p. 34.

${ }^{16}$ ISAIA, Cristiano Becker. Processo civil, atuação judicial e hermenêutica filosófica. $2^{a}$ edição. Curitiba: Ed. Juruá, 2011, p. 43.

${ }^{17}$ STRECK, Lenio Luiz. 0 que é isto - decido conforme minha consciência?. Porto Alegre: Ed. Livraria do Advogado, 2010, p. 101.

REDESG / Revista Direitos Emergentes na Sociedade Global - www.ufsm.br/redesg v. 1, n. 2, jul.dez/2012 Revista do Programa de Pós-graduaçÃo em DiREITO dA Universidade FEderal de SANTA MARIA - www.ufsm.br/ppgd
} 
instaura com o lingustic turns exige que, no interior da própria linguagem seja feito o controle hermenêutico.

E ele ${ }^{18}$ continua afirmando que

Entre outras coisas devemos levar o texto a sério, circunstância que se coaduna perfeitamente com as Constituições na segunda metade do século XX e confere especial especificidade á interpretação do direito, em face do vetor de sentido assumido pelo texto constitucional, além de afirma a autonomia do direito.

Mas o ponto onde ambos concordam (tanto Ovídio Baptista quando Lenio Luiz Streck) é que valorizar o fato concreto é uma atitude democrática que deve ser cultuada, pois só assim, haverá a superação da visão "instrumental-procedimentalista" que quer Lenio com a busca pela justiça que pretende Ovídio ${ }^{19}$ ao afirmar que

A justiça, para desgosto dos nossos teóricos, não poderá ser normatizada. Haverá de ser descoberta laboriosamente em cada caso concreto, observados, porém determinados critérios capazes de evitar que a natural (e inevitável) discricionariedade do ato judicial se transforme em arbitrariedade.

O fenômeno da globalização econômica que, com o desenvolvimento das Novas Tecnologias da Comunicação e da Informação (NTICs), se transformou numa globalização social, política e por que não dizer jurídica, deve influenciar essa virada hermenêutica do processo civil, como uma forma de sumarizar democraticamente de forma constitucionalmente adequada o velho procedimento ordinário-plenário-declaratório.

No final do século passado inúmeros "acontecimentos de importância histórica ímpar transformaram o cenário social da vida humana, dentre eles uma revolução tecnológica concentrada nas tecnologias da informação e da comunicação começou a remodelar a base da sociedade em ritmo extremamente acelerado."20

Segundo Castells ${ }^{21}$ a denominada "sociedade informacional" pode ser caracterizada como o surgimento de uma estrutura social associada a um novo modo de desenvolvimento, 0

\footnotetext{
${ }^{18}$ Idem, ibidem, p. 102.

${ }^{19}$ SILVA, Ovídio A. Baptista da. Epistemologia das ciências culturais. Porto Alegre: Ed. Verbo Jurídico, 2009 , p. 86.

${ }^{20}$ CASTELLS, Manuel. A Era da Informação: Economia, Sociedade e Cultura V. 01: Sociedade em Rede. $14^{\mathrm{a}}$ Reimpressão com novo Prefácio. Rio de Janeiro: Zahar, 2003-A, p. 39.

${ }^{21}$ Idem, ibidem, p. 39.

REDESG / Revista Direitos Emergentes na Sociedade Global - www.ufsm.br/redesg v. 1, n. 2, jul.dez/2012 Revista do Programa de Pós-graduaçÃo em DIREITO dA Universidade Federal de SANTA MARIA - www.ufsm.br/ppgd
} 
REVALORIZAÇÃO DO FATO NO AMBIENTE PROCESSUAL CIVIL BRASILEIRO: COMO A HERMENÊUTICA FILOSÓFICA E O PROCESSO CIVIL SE RELACIONAM MESMO NA SOCIEDADE INFORMACIONAL (SOCIEDADE EM REDE)

FELIPE STRIBE DA SILVA

informacionalismo, historicamente moldado pela reestruturação do modo capitalista de produção, no final do século XX.

Essa nova estrutura social criou uma nova forma de cultura que pode ser identificada com o conceito de "universal sem totalidade"22:

Nesta proposição, o universal significa a presença virtual da humanidade em si própria. 0 universal inclui o aqui e agora da espécie, o seu ponto de encontro, um aqui e agora paradoxal, sem lugar nem tempo claramente assinaláveis. 0 que é então totalidade? Trata-se na minha linguagem, da unidade estabilizada do sentido de uma diversidade. Que esta unidade ou esta identidade sejam orgânicas, dialéticas ou complexas mais do que simples ou mecânicas não altera nada: trata-se sempre de uma totalidade, isto é uma compartimentação semântica englobante.

Com o surgimento da rede mundial de computadores (Internet) passou-se a identificar um espaço não local chamado de Ciberespaço, que no entender de Pierre Lévy ${ }^{23}$

É o pulular das suas comunidades, o emaranhado de suas obras, como se toda a memória dos homens se desdobrasse nesse instante: um imenso ato de inteligência coletiva sincronizando, convergindo para o presente, relâmpago silencioso, divergente convergindo como uma cabeleira de neurônios.

Conforme afirma Manuel Castells ${ }^{24}$ :

A sociedade em rede também se manifesta na transformação da sociabilidade. 0 que nós observamos, não é ao desaparecimento da interação face a face ou ao acréscimo do isolamento das pessoas em frente dos seus computadores. Sabemos, pelos estudos em diferentes sociedades, que a maior parte das vezes os utilizadores de Internet são mais sociáveis, têm mais amigos e contatos e são social e politicamente mais ativos do que os não utilizadores. Além disso, quanto mais usam a Internet, mais se envolvem, simultaneamente, em interações, face a face, em todos os domínios das suas vidas.

Mas nessa relação simbiótica com as tecnologias devemos atentar para o fato de que a sociedade atual é que dá forma à tecnologia de acordo com as necessidades, valores e interesses

\footnotetext{
${ }^{22}$ LÉVY, Pierre. Cibercultura. Lisboa: Piaget, 2005, p. 273 e 274.

${ }^{23}$ Idem, ibidem, 276

${ }^{24}$ CASTELLS, Manuel. A sociedade em rede v. 1. 11. ed. Traduzido por Roneide Venâncio Majer. São Paulo: Paz e Terra, 2008, p. 23.

REDESG / Revista Direitos Emergentes na Sociedade Global - www.ufsm.br/redesg v. 1, n. 2, jul.dez/2012

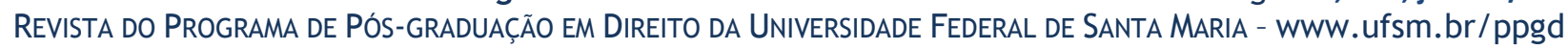


REVALORIZAÇÃO DO FATO NO AMBIENTE PROCESSUAL CIVIL BRASILEIRO: COMO A HERMENÊUTICA FILOSÓFICA E O PROCESSO CIVIL SE RELACIONAM MESMO NA SOCIEDADE INFORMACIONAL (SOCIEDADE EM REDE)

FELIPE STRIBE DA SILVA

das pessoas que utilizam as tecnologias. Além disso, as tecnologias de comunicação e informação são particularmente sensíveis aos efeitos dos usos sociais da própria tecnologia ${ }^{25}$.

Assim a tecnologia, pois si só não promove grandes alterações, ela precisa de uma mudança da pré-compreenção dos indivíduos que participam dos processos políticos, no ambiente informacional, mormente do processo civil, que não deixa de ser um processo político.

Como identifica o importante sociólogo ${ }^{26}$ :

De fato, nós temos já um considerável corpo de conhecimentos recolhidos na última década por investigadores acadêmicos, por todo o mundo, sobre as dimensões fundamentais da sociedade em rede, incluindo estudos que demonstram a existência de fatores comuns do seu núcleo que atravessam culturas, assim como diferenças culturais e institucionais da sociedade em rede, em vários contextos. $\dot{E}$ pena que os jornalistas, os políticos, os atores sociais, os líderes econômicos e os decisores continuem a falar de sociedade de informação ou sociedade em rede, ou seja, o que for que queiram chamar-lhe, em termos de futurologia ou jornalismo desinformado, como se essas transformações estivessem ainda no futuro, e como se a tecnologia fosse uma força independente que deva ser ou denunciada ou adorada. Os intelectuais tradicionais, cada vez mais incapazes de compreender o mundo em que vivem, e aqueles que estão minados no seu papel público, são particularmente críticos à chegada de um novo ambiente tecnológico, sem na verdade conhecerem muito sobre os processos acerca dos quais elaboram discursos. (CASTELLS, 2008, p. 18)

Assim, discursos sobre o processo eletrônico, sobre a informatização da justiça pública, deve partir de um repensar desse processo ainda extremamente arraigado a um paradigma da modernidade, sob pena de se discutir procedimento em detrimento da substância, afastando ainda mais o ambiente processual da referida sociedade, sendo está em rede ou não.

Por isso que a transformação do papel do magistrado, que sim é um objetivo do estado social, não pode se dar dentro de sua consciência, mas sim através de uma proximidade com o fato, pois só tendo um contato com o fato concreto (que não pode ser cindido do direito) é que ele poderá compreender/interpretar/aplicar o direito constitucionalmente adequado, tendo em vista a gama de princípios que legitimamente contenham valor ético-políticos da sociedade.

Assim é preciso uma nova visão do processo civil que acabe com a divisão, nitidamente liberal-burguesa, entre o juiz (enquanto interprete) e o caso levado a jurisdição (enquanto fato concreto), instituindo-se assim uma filosofia no processo civil brasileiro, para além de uma filosofia do processo.

\footnotetext{
${ }^{25}$ Idem, ibidem, p. 18

${ }^{26}$ Idem, ibidem.
}

REDESG / Revista Direitos Emergentes na Sociedade Global - www.ufsm.br/redesg v. 1, n. 2, jul.dez/2012

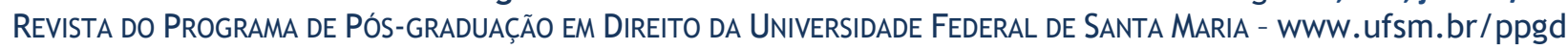




\section{CONCLUSÃO}

O processo civil brasileiro atualmente encontra-se e um momento extremamente paradigmático, invariavelmente ele sofre influências da Sociedade Informacional ou "Sociedade em Rede" (Manuel Castells), e busca adaptar-se a realidade dos novos meios de comunicação, mas mesmo assim, ele permanece preso a antigos dogmas do passado, como a plenariedade, a cognição exauriente, a ordinariedade, a visão eminentemente declaratória e repressiva, a cisão entre julgamento e instrução, mas sem dúvida o maior apego do processo civil brasileiro ainda é pela cisão (inexistente) entre "questões de fato" e "questões de direito".

Essa cisão desconhece ou aparenta desconhecer que o Direito é um Fato que se constrói historicamente, ele não é uma categoria específica, e que a noção investigativa que está na natureza do processo como ele primordialmente foi pensado ainda na época dos interditos romanos, determina que ele procure valorizar os fatos, pois estes são o principal objetivo do procedimento, e não simplesmente uma hipostasiação metafísica de uma categoria (inexistente de forma autônoma) que seria o direito.

Dessa forma para que realmente o processo civil evolua com a sociedade informacional é necessário que ele se permita transformar pelo ontological turn (giro-ontológico), ou invasão da filosofia no mundo prático, sempre tendo como condição de possibilidade a linguagem, e uma possibilidade, no caso de proteção de direitos sociais, é a sumarização democrática proposta pelo pesquisador e professor gaúcho Cristiano Becker Isaia, na obra "Processo Civil, Atuação Judicial e Hermenêutica Filosófica".

\section{REFERÊNCIAS}

BONAVIDES, Paulo. Ciência Política, 10 ed. Malheiros, São Paulo, 1999.

CASTELLS, Manuel. A Era da Informação: Economia, Sociedade e Cultura V. 01: Sociedade em Rede. 14 ${ }^{a}$ Reimpressão com novo Prefácio. Rio de Janeiro: Zahar, 2003-A.

FARALI, Carla. A filosofia do Direito Contemporâneo. Madrid: Hispania Libros, 2007.

ISAIA, Cristiano Becker. Processo civil, atuação judicial e hermenêutica filosófica. $2^{a}$ edição. Curitiba: Ed. Juruá, 2011.

LÉVY, Pierre. Cibercultura. Lisboa: Piaget, 2005

REDESG / Revista Direitos Emergentes na Sociedade Global - www.ufsm.br/redesg v. 1, n. 2, jul.dez/2012

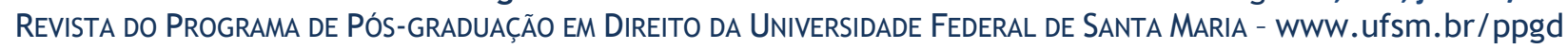


LUCAS, Doglas Cesar. A crise funcional do Estado e o cenário da Jurisdição desafiada. In: MORAIS, José Luís Bolzan de. O Estado e suas crises. Porto Alegre: Livraria do advogado, 2005.

SGARBI, Adrian. Clássicos da teoria do Direito. Rio de Janeiro: Lúmen Júris, 2006.

SILVA, Ovídio A. Baptista da. Epistemologia das ciências culturais. Porto Alegre: Ed. Verbo Jurídico, 2009.

STRECK, Lenio Luiz. 0 que é isto - decido conforme minha consciência?. Porto Alegre: Ed. Livraria do Advogado, 2010.

STRECK, Lenio Luiz. OLIVEIRA, Rafael Tomaz de. 0 que é Isto vol. 02 - Garantias Processuais Penais. Porto Alegre: Livraria do Advogado, 2012.

STRECK, Lenio Luiz; MORAES, José Luiz Bolzan. Ciência Política e Teoria Geral do Estado, $5^{a}$ Edição, Ed. Livraria do Advogado, 2009.

Recebido em: 14.11.2012

Revisado em 05.02.2013

Aprovado em: 18.02.2013 